\title{
Les relations culturelles bulgaro-roumaines
}

Une rétrospective

\section{Evelyne Enderlein}

\section{OpenEdition}

\section{Journals}

Édition électronique

URL : https://journals.openedition.org/cher/7859

DOI : $10.4000 /$ cher.7859

ISSN : 2803-5992

Éditeur

Presses universitaires de Strasbourg

\section{Édition imprimée}

Date de publication : 1 décembre 2009

Pagination : 23-28

ISBN : 978-2-35410-006-3

ISSN : 1968-035X

\section{Référence électronique}

Evelyne Enderlein, «Les relations culturelles bulgaro-roumaines », reCHERches [En ligne], 3 | 2009, mis en ligne le 15 décembre 2021, consulté le 17 décembre 2021. URL : http://journals.openedition.org/ cher/7859 ; DOI : https://doi.org/10.4000/cher.7859

\section{(c) (i) (2)(2)}

Ce(tte) œuvre est mise à disposition selon les termes de la Licence Creative Commons Attribution Pas d'Utilisation Commerciale - Partage dans les Mêmes Conditions 4.0 International. 


\title{
Les relations culturelles bulgaro-roumaines Une rétrospective
}

EVELYNE ENDERLEIN

Université de Strasbourg

\begin{abstract}
ui s'intéresse aux relations culturelles bulgaro-roumaines doit remonter le temps d'au moins sept siècles. Celles-ci se sont développées dès le XIve siècle, du fait même de la proximité géographique des deux pays voisins situés en aval du Danube, ainsi que de leur histoire politique et spirituelle fort proche. Dès le XIve siècle, la culture et la littérature byzantino-slaves se sont répandues sur le territoire actuel de Roumanie grâce à la littérature bulgare qui a ainsi exercé une très forte influence sur la jeune littérature roumaine. Soulignons également que les Roumains, convertis aussi à la branche orthodoxe du christianisme, ont utilisé le vieux bulgare en tant que langue officielle jusqu'au $\mathrm{XvI}^{\mathrm{e}}$ siècle, ainsi que l'alphabet bulgare cyrillique jusqu'au $\mathrm{XIX}^{\mathrm{e}}$ siècle, pour adopter alors les caractères latins modifiés.

En 1396, la Bulgarie tombe sous la domination ottomane, ainsi que les principautés de Moldavie et de Valachie, fondées au début du XIve siècle. Ces dernières gardent cependant une certaine autonomie interne, ce qui explique que des Bulgares aient émigré sur les territoires actuels de la Roumanie dès les premières années de la domination; grâce à la bienveillance des Roumains, menacés par le même danger ottoman, ils purent conserver et développer leur culture. C'est ainsi que les hommes de lettres bulgares, émigrés au nord du Danube, purent continuer à écrire dans leur langue, et, jusqu’au début du $\mathrm{xx}^{\mathrm{e}}$ siècle, un nombre considérable de livres, pour la plupart religieux, furent traduits du vieux bulgare en roumain.
\end{abstract}


En 1859, Alexandru Ioan Cuza est élu prince des principautés de Valachie et de Moldavie et, le 24 décembre 1861, il déclare l'Indépendance de la Roumanie, qui ne sera définitivement reconnue qu'après la fin de la guerre turco-russe en 1877.

Le $\mathrm{XIX}^{\mathrm{e}}$ siècle est le moment où se forment les nations de l'Europe du Sud-Est et où s'éveille leur conscience. En Bulgarie, nous assistons à un réveil particulièrement fort, les relations bulgaro-roumaines s'intensifient dans le cadre du vaste mouvement populaire de libération des peuples des Balkans. Notons que les XVIII ${ }^{\mathrm{e}}$ et XIX ${ }^{\mathrm{e}}$ siècles sont marqués dans cette région par de fortes migrations qui entraînent un brassage des populations, ce qui va conduire à l'apparition de minorités au sein de grands ensembles ethniques. Ainsi, au début du XIX ${ }^{\mathrm{e}}$ siècle, la Roumanie devint le principal centre culturel et religieux des immigrés bulgares qui trouvaient sur les territoires septentrionaux du Danube un refuge et jouissaient de liberté (Velichi, 1970).

C'est en Roumanie, à Bucarest et à Braila que les révolutionnaires bulgares purent former les organisations politiques les plus importantes et les plus actives, dont le but était la libération de la Bulgarie de la domination ottomane (Velichi, 1979; Трайков, Жечев,1986). C'est de là qu'ils organisèrent des troupes d'insurgés qui partirent en Bulgarie pour affronter l'armée turque. En 1866, les immigrés bulgares fondent un Comité central bulgare secret de libération dans la capitale roumaine (Бурмов, 1950).

Concurremment, ils organisent tout un système d'institutions culturelles - des écoles, des imprimeries, des éditions périodiques, des cercles politiques, scientifiques et littéraires. Il faut noter aussi que la première société philologique bulgare est fondée en Roumanie dans les années vingt du XIX ${ }^{\mathrm{e}}$ siècle à Braşov. Plus tard, en 1869, est fondée à Braila la première société scientifique bulgare. La société bulgare des Lettres sera transférée à Sofia seulement après la libération de la Bulgarie et deviendra l'Académie des sciences bulgare (Арнаудов 1966; Паскалева 1971: 5-27).

C'est également en Roumanie que fut formée la première troupe théâtrale professionnelle - celle de Dobri Voynikov - le fondateur du théâtre bulgare. De même, une grande partie des œuvres de la nouvelle littérature bulgare furent créées en Roumanie, si bien que l'on peut parler d'une véritable communauté littéraire bulgare en exil roumain (Siupiur, 2006: 35-44).

Cette immigration littéraire jouera un rôle important dans le transfert littéraire entre la littérature bulgare et roumaine. Le bilinguisme (bulgare 
et roumain) des écrivains bulgares à cette époque-là est d'une importance primordiale pour les échanges culturels. Parmi les noms les plus représentatifs nous pouvons citer: Petar Beron, Dimitar Veliksin (il écrit des poèmes en français, roumain et bulgare, reconnu comme poète roumain, il a des publications dans des éditions périodiques bulgares aussi), Georgi Rakovski, Lyuben Karavelov, Khristo Botev, Ivan Vasov. Remarquons au passage que certains intellectuels roumains apprennent la langue bulgare grâce à leur collaboration avec les hommes de culture bulgares, comme, par exemple, le scientifique et écrivain B.P. Hasdeu (Сюпюр 1980: 28).

Les immigrés bulgares participent activement à la vie politique, sociale et culturelle roumaine. C'est par l'intermédiaire de la littérature et de la culture roumaines que la littérature et la culture bulgares s'approprient les valeurs modernes européennes, importées surtout de France. Comme le montrent les études de spécialistes bulgares et roumains tels que Iliya Konev, Hélène Siupiur, Stephana Tarinska etc., ce sont les intellectuels bulgares immigrés en Roumanie qui ont exporté les valeurs européennes en Bulgarie même (Конев 1983, 1991, 1998, 2003; Сюпюр 1982, 1999; Таринска, 1969, 1999).

Cependant le processus d'influences n'est pas unilatéral. Comme les chercheurs roumains le soulignent, une grande partie de l'intelligentsia bulgare s'était intégrée dans le système des institutions culturelles roumaines, devenant médecins, ingénieurs, journalistes, professeurs, avocats, imprimeurs, employés dans les transport ferroviaires (Сюпюр, 1980).

Après la libération de la Bulgarie en 1878, nombre d'entre eux reviennent dans leur patrie, d'autres restent en Roumanie - comme Georgi Pechakov, Ivan Kasabov, Dimitar Agoura, etc. - et ceux-là mêmes qui ont fait leurs études en Bulgarie, introduisent en Roumanie l'esprit bulgare, les idéaux des émigrants de l'époque du Réveil national bulgare.

À partir de l'année 1878, les identités nationales des deux sociétés et États - bulgares et roumains - sont formées. Les historiens notent que ces phénomènes migratoires au sud et au nord du Danube et les contacts permanents ont favorisé aussi bien le rapprochement que la distanciation (Danova, 1995: 3-25; Нягулов, 2003: 183-208). Tant que les deux pays étaient liés par des buts politiques communs, corrélatifs de l'émancipation nationale par rapport à l'Empire ottoman, ils excluaient toute confrontation dans leurs relations bilatérales. Mais dès l'affranchissement du joug commun, apparaissent des sources de concurrence et des intérêts contradictoires, liés surtout aux problèmes de territoires et de minorités. Ceux-ci se perpétuent jusqu'à la deuxième guerre mondiale, le principal consistant en 
la revendication de la Dobroudja par les deux pays (Милетич, 1918: 69-118; 1927: 59-100; Mutafciev, 1932).

La confrontation entre les deux pays atteint son apogée au cours de la deuxième guerre des Balkans en 1913 et pendant la première guerre mondiale. En 1878, au congrès à Berlin, la Dobroudja est annexée à la Roumanie et une bande de terre - qu'on appellera Dobroudja du Sud - à la Bulgarie. Après la deuxième guerre des Balkans, la Bulgarie est forcée de céder Dobroudja du Sud à la Roumanie. Suite au traité de Neuilly, signé a la fin de la Premiere guerre mondiale en 1919 entre la Bulgarie et l'Alliance, la Dobroudja entière devient un territoire roumain. Malgré tout, le contrat imposé par l'Allemagne à Craiova en 1940, obligera la Roumanie à rendre Dobroudja du Sud à la Bulgarie.

Il en résulte des ressentiments, des stéréotypes négatifs développés par les propagandes nationales, surtout après la restauration du pouvoir d'État dans les deux pays (Нягулов, 2003: 198-202).

L'élite roumaine, confortée par la thèse de son origine latine, se mit à nourrir une attitude de supériorité par rapport aux peuples balkaniques voisins. De son côté, l'idée nationale bulgare se construisait sur la puissance politique du vieil État bulgare médiéval qui avait conquis le territoire de la Roumanie à l'époque où l'État roumain n'était pas encore constitué, ainsi que sur la mission culturelle que l'État bulgare accomplissait non seulement vis-à-vis de certains peuples slaves, mais aussi des Roumains.

Ce n'est qu'à la fin de la guerre, en 1947, que l'alignement de Bucarest et de Sofia sur Moscou a réintroduit la notion d'amitié entre les deux pays désormais déclarés "frères et solidaires" avec l'Union soviétique contre les démocraties occidentales. Comme le montrent des recherches récentes, cette unité de choix dans les deux pays fut à la fois imposée et choisie: imposée par la politique impériale des grandes puissances: l'URSS (intéressée et usurpatrice), la Grande-Bretagne et les États-Unis d'Amérique (passifs et inefficaces), choisie par les communistes qui réclament et accomplissent les conseils et les directives de Moscou, bâtissent docilement la société socialiste développée, consentant et participant à la répression de leurs propres élites jusqu'à la fin des années quatre-vingt, où on a vu s'effondrer l'édifice imaginaire du socialisme et ressurgir le problème des minorités respectives.

Durant les années quatre-vingt-dix, l'unique réalisation concernant les minorités dans les relations bulgaro-roumaines a été l'ouverture en l'année scolaire 1999-2000 d'un établissement d'enseignement secondaire (lycée) bulgare à Bucarest et d'une école d'enseignement secondaire (lycée) roumaine 
à Sofia. Cet acte s'est accompli à l'initiative de la partie roumaine, sur la base d'un accord entre les représentants des Ministères de l'éducation. Les deux établissements sont censés enseigner la langue maternelle des communautés minoritaires des deux pays. En réalité, à cause du processus d'assimilation ou du manque d'origine minoritaire, pour la majorité des élèves la langue respective représente une langue étrangère. L'avenir des deux écoles dépend de la bonne volonté des deux gouvernements. La pratique internationale des traités et des accords bilatéraux en faveur de la protection des minorités influencera probablement le règlement plus clair de la problématique entre la Bulgarie et la Roumanie.

De nouveau, Bulgares et Roumains se retrouvent confrontés à une même réalité historique qui leur propose un but commun, une voie de développement commune sur les principes de loyauté, de tolérance, de coopération, ancrés cette fois-ci au sein de la communauté européenne. Dans ce contexte et sur le fond de la mondialisation, il reste à espérer que l'observation de ces principes préservera les peuples bulgare et roumain, comme l'ensemble des Européens, des passions absurdes qui, au prix incalculable de vies humaines, ont accompagné l'affirmation de leur identité.

\section{Bibliographie}

Bocholier, François, 2001, «La Dobroudja entre Bulgarie et Roumanie (1913-1919): regards français", Etudes balkaniques, Sofia, 37e année, n 2-3, p. 64-81.

Danova, Nadja, 1995, "L'Image de 'l'autre' dans les manuels bulgares du XIX et le debut $\mathrm{Xx}^{\mathrm{e}}$ siècle", Études balkaniques, 1995, n² 2, p. 3-25.

Mutafciev, Petar, 1932, Bulgares et Roumains dans l'histoire des pays danubiens. Sofia.

Njagulov, Blagovest, 2006, «Les minorités 'réciproques' en Bulgarie et en Roumanie à l'époque actuelle»: similitudes et divergences. Etudes balkaniques, Sofia, $42^{\mathrm{e}}$ année, ${ }^{\circ} 1$, p. 3-9.

Siupiur, Elena, 2006, «La culture et les élites de la communauté bulgare en Roumanie, Études balkaniques, Sofia, $42^{\mathrm{e}}$ année, $\mathrm{n}^{\circ} 1, \mathrm{p} .5-44$.

Siupiur, Elena, 2006, «Les fonctions et la mission politique des intellectuels en Europe du Sud-Est au XIx ${ }^{\mathrm{e}}$ siècle», Études balkaniques, n³-4, 42e année, p. 163-179.

Velichi, Constantin, 1970, La contribution de l'émigration bulgare de la Valachie à la renaissance politique et culturelle du peuple bulgare (1762-1850), Bucureşti, Ed. Academiei. 
Velichi, Constantin, 1979, La Roumanie et le mouvement révolutionnaire bulgare de libération nationale (1850-1878), Bucureşti, Ed. Academiei.

Арнаудов, Михаил,1966, Българското книжовно дружество в Браила, 1869-1876, София, Издателство на БАН.

Бурмов, Александър, 1950, Българският революиионен иентрален комитет, София.

Българо-румънски титературни взаимоотношения през XIX век, 1980, София, Издателство на Българската академия на науките.

Великсин, Димитър, 1999, Димитър Великсин. Съчинения,1999, Под редакцията на Стефана Таринска и Родя Флоря, София, ИК “Проф. Марин Дринов”.

Жечев, Николай, 1971, Браила и българското културно-национално възраждане. София, БАН.

Жечев, Николай,1991, Букурещ - културно средище на българите през Възраждането, София, БАН.

Конев, Илия, 1983, 1991, 1998, 2003, Българското Възраждане и Просвещението, Т. I - III, София, БАН.

Милетич, Любомир, 1918, “Българи и румъни в техните културно-исторически отношения”, in Добруджа, София.

Младенов, Стефан, 1927, “Румъно-българските културни влияния и румънските учени” in Силистра и Добруджа, София.

Нягулов, Благовест, 2003, “Румънците и Румъния в българската книжнина (1878-1989)" in Николай Аретов, Балканските идентичности в българската култура, София, Издателство “Кралица Маб”, р. 183-208.

Паскалева, Вирджиния, 1971, “Българското книжовно дружество в Браила (1869-1876)" in История на Българската академия на науките 1869-1969, София, БАН, р. 5-27.

Сюпюр, Елена, 1980, “Типологически черти на румъно-българските литературни взаимоотношения през XIX в." in Българо-румънски титературни взаимоотношения през ХІХ век, София, БАН, р. 23-34.

Сюпюр, Елена, 1982, Българската емигрантска интелигениия в Румбния през ХІХ век, София, БАН.

Сюпюр, Елена, 1999, Българските училища в Румъния през ХІХ век, София, БАН.

Таринска, Стефана, 1966, Прозата на Христо Ботев, София, Наука и изкуство.

Трайков, Веселин еt Николай Жечев, 1986, Българската емиграция в Румъния, XIV век - 1878 г. и участието й в стопанския, обществено-политическия и културния живот на румънския народ, София, Наука и изкуство. 